Bond University

Research Repository

\title{
Critical perspectives on brand culture in the era of participatory and algorithmic media
}

Carah, Nicholas; Brodmerkel, Sven

Published in:

Sociology Compass

DOI:

10.1111/soc4.12752

Licence:

Other

Link to output in Bond University research repository.

Recommended citation(APA):

Carah, N., \& Brodmerkel, S. (2020). Critical perspectives on brand culture in the era of participatory and algorithmic media. Sociology Compass, 14(2), [e12752]. https://doi.org/10.1111/soc4.12752

\section{General rights}

Copyright and moral rights for the publications made accessible in the public portal are retained by the authors and/or other copyright owners and it is a condition of accessing publications that users recognise and abide by the legal requirements associated with these rights.

For more information, or if you believe that this document breaches copyright, please contact the Bond University research repository coordinator 
Critical perspectives on brand culture in the era of participatory and algorithmic media

Keywords: Brands, branding, consumer participation, algorithmic culture, digital media platforms, social media

\begin{abstract}
Brands have become a ubiquitous feature of life in market-based consumer societies. While marketers aim to establish brands as efficient devices for guiding purchase decisions, critical scholarship investigates how branding functions as a mode of exercising power by shaping consumers' identities and consumer culture more broadly. Beginning in the 1950s as a predominantly semiotic critique of advertising, critical research into branding has over the decades developed a more complex conceptualisation of brands and their interrelationship with 'active' audiences and the cultural environment in which they operate. The first part of this essay summarises this conceptual evolution. It provides the necessary background for interrogating how brands engage with, shape, and capitalise on 'algorithmic culture' (Striphas, 2015). Recent dramatic changes in the data-processing power of the developing algorithmic, platform-dominated media environment is significantly altering the way brands operate and capitalise on consumer participation and popular culture. The present moment is therefore a crucial one to survey and evaluate emerging critical perspectives on brands and branding. By engaging with the current scholarship on social media, algorithms and platforms, the second part of this essay outlines a number of novel and distinctive critiques emerging from this literature, which can help inform further research.
\end{abstract}

\title{
Introduction
}

Brands are central to social and economic life in contemporary capitalist societies. Brands are 'sophisticated networks of information, associations and feelings' (Berthon et al., 2003) created by marketers to control the process of attaching qualities to products, experiences and services (Lury, 2004; Hawkins, 2009). How brands are built, managed and sustained over time has attracted extensive research in the field of marketing and business management (paradigmatically: Aaker, 1996). At the same time, there is a long history of critical research 
into branding (Ewen, 1976; Wernick, 1991; Goldman and Papson, 1996; Klein, 2000). While so-called 'administrative research' (Lazarsfeld, 1941) in the field of advertising and marketing is interested in supporting marketers in their desire to make brands more efficient, effective and valuable, all critical approaches - regardless of their specific scholarly tradition and focal areas - examine and critique the processes that lead to and maintain the unequal distribution of resources and power in society. Thus, when critical scholars argue that we live in a 'brand culture' (Banet-Weiser, 2012) or 'brand society' (Kornberger, 2010), they are not only observing that our cultural worlds are saturated by brands. They are also seeking to understand how the pervasiveness of branding in our culture affects our identifications and imaginations, our political subjectivities, and the distribution of power and resources. The task of a critical analysis of brands is thus two-fold: First, to critically interrogate the exercise of brands' power to shape culture and organise markets and, second, to imagine how those power relationships might be different (Andrejevic, 2009). Critical accounts of branding might join up with political efforts to change the functioning of markets - their labour relations, their cultural and aesthetic qualities, their ecological impacts, and so on. In short, critical perspectives on brands focus their attention on how branding operates as a mode of exercising power by shaping culture and organising markets, and what problems arise from the manner in which communication resources are organised in - and organise - social life (Hardy, 2017).

Both marketers (Vargo and Lusch, 2004; Prahalad and Ramaswamy, 2004; Conejo and Wooliscraft, 2015) as well as critical scholars (Arvidsson, 2005; Foster, 2008; Holt, 2002; Lury, 2004) have come to see brands as open-ended or multi-dimensional social and cultural processes that rely on the participation of 'active' consumers and other cultural actors to create meaning and value. Marketers celebrate the co-creative potential of consumers and their potential to serve as a reservoir for potential future product and marketing innovations. Critical scholars, on the other hand, examine how brands 'engage' us in the social process of incorporating brands into our lives and how branding becomes a general - and, for various reasons, problematic - logic for the communication of our identities (Moor, 2003; Hearn, 2008; Banet-Weiser, 2012). Brand critique that takes consumer participation into account therefore involves more than the semiotic analysis of advertisements and their purported persuasive, ideological effect on 'passive' consumers - an approach which dominated the critical research into advertising and branding from the late 1950s to the 1990s. Rather, it requires paying attention to how marketers design 'regimes of engagement' that harness 
consumers' creative self-expression in ways that strategically benefit the brand, but which at the same time appear to preserve their freedom and autonomy (Serazio, 2013; Zwick et al., 2008).

Taking this now well-established conceptualisation of brands as open-ended socio-cultural processes as a starting point, the goal of this article is twofold: First, we provide a brief overview of the evolution of critical research into brands from its initial focus on symbolic representation to its more recent attention to consumer participation and the co-creation of brands. Second, we outline how in the past decade branding has decisively shifted from a 'mass' to a 'platform' logic. The present moment is a crucial one to survey critical perspectives on brands because dramatic changes in the participatory qualities and dataprocessing power of digital media is altering how brands operate. Participatory forms of branding now operate within the algorithmic logic of a data-driven media environment. By employing increasingly sophisticated machine-learning technologies, brands and media platforms like Google, Facebook or Amazon act in the world by classifying, simulating and ordering culture in ever more fine-grained ways. This challenges us to re-assess critical accounts of brands and branding: What are productive critiques of branding in an era in which they saturate everyday life more than ever, but are also more capable of harnessing our participation, targeting particular moments, and creating a reflexive set of engagements with consumers? The main section of this essay explores how recent critical perspectives on branding have addressed the participatory and data-processing qualities of digital media and considers the relevant current literature on social media, algorithms and platforms for interrogating how brands engage with, shape, and capitalise on 'algorithmic culture' (Striphas, 2015).

\section{From symbolic persuasion to co-creation and participation}

Critical perspectives on advertising, branding and consumer culture are organised around the central critical streams of media and communication research. These can be broadly characterised as a 'political economy' approach and a 'cultural' approach. The critical political economy approach investigates the extent to which advertising, as a system of financing media, impacts on media provision and influences the range and nature of media content produced. Consequently, scholars working in this tradition explore the interrelationship between commercial media, major corporations, and marketing departments 
or their advertising agencies (Murdock and Golding, 2005; Mosco, 2009; Hardy, 2014; 2017). Political economy research has drawn attention to two simultaneous trends related to the increasing dominance of digital media platforms. There is, first, the blurring of editorial content and advertising, most prominently in the form of so-called 'native advertising'. This trend towards closer content integration coexists with the increasing disaggregation of media and advertising due to the opportunities that media platforms provide to target consumers directly and thereby allowing marketers to cut out media publishers as the traditional intermediary between advertisers and audiences (see summarily Hardy, 2017). These developments raise new concerns about the lack of transparency with regard to advertisers' potential influence on editorial content and the increasing invasion of consumers' privacy as the result of the ever more sophisticated tracking technologies employed by platforms and marketers.

The second prominent critique of advertising and branding is a cultural-ideological one in which advertisements and brands take the form of symbolic texts that persuade consumers by attaching 'mythical' qualities to products (Barthes, 1977; Goldman and Papson, 1996; Ritzer, 1992). Beginning in the 1950s with seminal publications like Vance Packard's Hidden Persuaders (1957), the ideology critique of brands represents an effort to demystify the instrumental, fanciful or deceptive claims that brands make - deceptive when they attach qualities to products that do not exist, fanciful when they claim associations between the product and its consumers that are aspirational or idealistic. Consequently, critical forms of activism like 'culture jamming' (Carducci, 2006; Klein, 2000; Lasn, 1999) attempt to disrupt the semiotic appeals of advertisements and forge new ones that undermine brands.

Furthermore, critical scholars working in this tradition aim to expose how brands fetishize the social relationships inherent in the production and consumption of goods, services and experiences (paradigmatically: Klein, 2000). For instance, a fashion brand might conceal the sweatshop conditions in which a garment is produced, while at the same time presenting the qualities attached to the garment - for instance, that wearing it will make us glamourous - as intrinsic to the object, when these qualities are in fact socially and symbolically constructed judgments about what is desirable and beautiful. In short: These critical cultural perspectives and movements tacitly conceptualise the power of branding and advertising as symbolic. They illustrate how ideology critique is a valuable strategy for unravelling the semiotic appeals of brands, helping us to articulate how brands teach us to desire, frame our judgements, and integrate us into the rhythms of consumer culture. 


\section{Co-opting critique}

One of the seemingly paradoxical features of this popular critique of branding, advertising and consumer culture is that since the 1960s it has been enthusiastically and productively appropriated by marketers. The so-called 'creative revolution' in advertising was the response of advertisers to an increasing and widely diffused cynical consumer attitude. Instead of hailing consumers as passive 'dupes' susceptible to established forms of hard-sell persuasion, the advertisements of the creative revolution played to the savvy consumer by 'winking' at them that the advertiser 'knew they knew' the advertisement was attempting to persuade them (Frank, 1997; Holt, 2002). Most famously, the agency DDB, one of the pioneers of this savvy and ironic mode of advertising, violated existing conventions by creating a whole series of VW-ads in a humorously self-deprecating style, starting with the famous 'Think small' ad in 1959 (Marcantonio et al., 2014).

The lasting legacy of the creative revolution is, however, not so much a specific form of advertising appeal but, more fundamentally, an understanding of branding as an open-ended process that relies on the active participation of consumers as meaning-makers in the social process of creating brand value. While marketers can suggest attachments between meanings and products, those meanings only create value when consumers incorporate them into their own identities and practices. Brand value then is created via the social interplay between brands, consumers and cultural life. The ironically detached tone of DDB's celebrated VW ads was only the beginning of the broader trend of advertisers trying to 'capture' the expressive qualities of consumption by appealing to consumers' attitudes, beliefs and lifestyles. Take Coca-Cola as another illustrative example. From the mid-twentieth century onwards, the brand's advertisements began to say less about the purported 'therapeutic' qualities of the product and more about the kind of people that consumed it. The sociality of brands took on new dimensions, because the attachment being created by the brand was with the lifestyle and identity of the person consuming it. Coca-Cola's iconic 'I'd like to buy the world a Coke' advertisements from the early 1970 is a prominent example of this approach: The ad did not focus on the product, but rather on the hip countercultural politics of people who consumed it. Beginning with the 'creative revolution', advertisers realised that consumption is not just the process of judging the qualities of products and making selections based on these evaluations, but also of expressing tastes and values more broadly. They realised that these ever-shifting dynamics of consumer culture are not a threat to brands, but 
an opportunity for expansion and renewal. Marketers now explicitly regarded consumers' desire for novel and creative self-expression, for 'rebellious anti-consumerism' (Heath and Potter, 2005) or for 'authentic', ethical consumption (Banet-Weiser, 2012; Lewis and Potter, 2013) as crucial resources for brand innovation. For example, throughout the 1980s, brands like Adidas or Tommy Hilfiger capitalised on associations with the 'cool' hip-hop and street culture that were largely created outside of advertising agencies by African American artists and consumers (Klein, 2000). They also began experimenting with experiential, participatory and culturally-embedded forms of promotion like for example guerrilla marketing (Serazio, 2013). Similarly, in the 2000s, brands like Dove or Ben \& Jerry's appealed to consumers' desire for 'authenticity' by purportedly challenging the beauty stereotypes perpetuated by the cosmetics industry in the case of Dove, or even by openly expressing anti-capitalist sentiments in the case of Ben \& Jerry's (Cederström and Marinetto, 2013).

\section{Reflexive brands}

The culturally attuned and ironic style coming out of advertising's creative revolution is therefore best understood as advertisers' first attempt to make their promotional communication more reflexive and better suited to consumers increasingly regarded as unpredictable and sometimes resistant, but nearly always productive, sources of cultural knowledge and innovation. The creative revolution re-imagined advertising as an ongoing set of techniques that stimulate and then harness expressivity, creativity and relationality around the brand. The work of branding is therefore not so much to 'invent' specific sets of meaning that 'persuade' consumers, but to continuously attune brands to an ongoing process of meaning-making (Arvidsson, 2005, Lury, 2004, Hearn, 2008, Moor, 2003). Brands exercise control by providing 'cultural resources' (Holt, 2002) and by 'enabling and empowering the freedom of consumers so that it is likely to evolve in particular directions' (Arvidsson, 2005, p. 244). This is not to say that brands have ceased to exert power at the ideological level by shaping how we see ourselves and our relationships with one another - they most certainly continue to do so. Rather, it is to say that a critique focused exclusively on ideological readings of ads does not fully contain how brands exercise power. The creative revolution of the 1960s was arguably the last major change in the semiotic logic of brands. All the innovation since then has been focused on managing meaning-making in general by devising techniques that allow brands to recuperate and appropriate the transgressive and resistant actions of consumers who create unintended but still valuable extensions of the brand (Moor, 2003; Zwick et al., 2008). The contemporary digital media environment facilitates this 
process through the increasing capabilities of platforms and devices to stimulate and harness our participation and to convert cultural life into data that enables real-time monitoring and response (Zwick et al., 2008; Andrejevic, 2013). This shift requires the development of a post-ideological perspective on brands. This notion is not meant to imply that marketing discourses and advertising practices - even the participatory-algorithmic ones we describe in this article - no longer function at the level of ideology. What the term 'post-ideological' refers to here is a critical approach to branding that examines how brands exercise power beyond creating and disseminating specific symbolic messages. Their power is not only ideological or representational.

\section{Brand culture in the age of participatory and algorithmic media}

Brands on digital media platforms do not only exist as 'pre-packaged' texts such as display ads or promotional videos; the participatory and data-driven nature of digital media also turns them into more open-ended and malleable communicative processes. The first generation of critical accounts of promotional communication in the digital era tended to focus on either the participatory or the data-driven aspects of digital media. Theorists interested in the participatory affordances of interactive and social media paid close attention to the ways marketers enticed consumers to 'engage' with brands online and to co-create content, thereby embedding the brand more deeply into their everyday cultural practices and experiences (Moor, 2003; Kornberger, 2010; Arvidsson 2006; Banet-Weiser, 2012). Scholars focused on the data-processing capabilities of the evolving digital media environment on the other hand critically analysed how marketers utilised the 'digital enclosure' (Andrejevic, 2007) for collecting consumer intelligence, segmenting audiences, and for targeting audiences with increasingly personalised promotional messages (Zwick and Knott, 2009; Turow, 2011; Andrejevic, 2013; Couldry and Turow, 2014; Nadler and McGuigan, 2018). These accounts have drawn attention to the power imbalance inherent in these systems of economic surveillance. Audience members not only participate without sufficient means to control the extent to which their activities are being tracked; they also provide a form of 'free labour' (Terranova, 2000) which goes beyond the 'audience labour' associated with just watching advertisements, as initially conceptualised by Dallas Smythe (1977). We will elaborate this argument in more detail a little further down. 
Expanding on these first-generation accounts, recent critical work on the promotional and algorithmic nature of digital media platforms explores the interdependent and recursive nature of consumer participation and surveillance. It builds on the notion of 'algorithmic culture', which Striphas (2015, p. 396) defines as the increasing tendency to delegate the work of culture - the 'sorting, classifying and hierarchizing of people, places, objects and ideas' - to computational processes. Scholarship on algorithmic culture encourages us, firstly, to think 'infrastructurally' about culture (Beer 2013). It draws attention to the 'material pathways of cultural circulation' (Beer 2013, p. 14) in digital media environments and how the data-driven ordering of content characteristic for algorithmic platforms enables or constrains encounters with popular culture. In these perspectives digital media are infrastructure that organise cultural life. The infrastructure of digital media includes the devices we interact with and that collect data, the ordering of information in databases, the classification and manipulation of content by algorithms, and the creative practices consumers engage in when interacting with content. The infrastructure of digital media also extends to the way that data and their infrastructure become embedded in public and private spaces and tethered to our bodies.

Secondly, scholarship on algorithmic culture has begun to investigate the interplay between the algorithmically determined circulation and visibility of content and the dynamic and reflexive nature of consumer participation. This relationship has for example been conceptualised by documenting the labour undertaken by consumers and intermediaries like influencers on digital platforms. A significant facet of this labour is the work of imagining, addressing and pre-empting algorithmic targeting (Bucher 2017, Cotter 2019, Carah and Dobson 2016). Using digital media involves both generating the data that trains platform algorithms, and continuously making judgments and forming vernacular theories about how those algorithms sort, classify, afford and constrain action. To be visible in the flows of images and video on social media platforms users need to adopt a strategic promotional mindset by thinking about what kinds of performances, at what times, generate the engagement (in the form of likes, comments, reactions) that will make the content recognisable to recommendation algorithms. In the era of platforms, branding can be understood as a techno-cultural process that relies on the two-way capacity of consumers and influencers to translate their lived experience into 'data doubles' that train algorithms, and to make vernacular judgments that attune their practices to what they assume is the algorithmic logic of these platforms (Bucher, 2016; Cheney-Lippold, 2017; van der Nagel, 2018; Cotter, 
2018). Users are not simply passive targets of data-driven classification and customisation, they are also active participants who animate the interplay between the human capacity to affect one another and the algorithmic capacity to classify and predict.

The algorithmic brand culture that has emerged in the era of digital media platforms combines the participatory affordances and the data-processing power of digital media (Brodmerkel and Carah, 2016, Carah 2017, Carah and Angus 2018). A critical, postideological approach to branding in the era of participatory and algorithmic media therefore interrogates the ways in which brands manage the flow of content and affect in algorithmic culture. It pays close attention to the social and technical processes through which brands operate in 'open-ended' ways by constructing devices for cultivating and harnessing consumer productivity (Lury, 2004; Foster, 2008). Such a critique focuses less on the content of texts and more on how brands use media of all kinds as infrastructure for anticipating and productively appropriating consumer creativity. Once brands rely on the open-ended creative capacities of consumers to create value, they become 'programming devices' (Lury, 2004) that modulate consumer action. By adopting such an infrastructural perspective, we can understand digital media as participatory, algorithmic and logistical tools for monitoring, preempting and organising consumer culture.

In what follows we identify three distinctive critical perspectives on branding emerging at this intersection of cultural-participatory and analytical-predictive techniques. The algorithmic brand culture of digital media is (1) characterised by the interplay between the open-ended and creative capacities of participants and the calculative capacities of media platforms, (2) organised around harnessing the productive labour of consumers and (3) animated by a conceptualisation of media as infrastructure for organising consumer productivity.

\section{Calculated participation}

Prior to digital media brands could only harness participation in small-scale ways like wordof-mouth or guerrilla marketing tactics, or they could use cultural researchers like so-called 'coolhunters' (Gladwell, 1997) to track novel appropriations of brands and reincorporate them into product design and mass media campaigns. Digital media though allow for consumers and cultural participants to produce representations of the brand that are seen at scale and for consumer innovations with the brand to be monitored and leveraged in real- 
time. Take the examples of Instagram influencers and Snapchat's sponsored filters. In the case of Instagram influencers, the brand can partner with consumers and cultural intermediaries with large followings, creating cultural events or providing products that the influencers incorporate into the images and videos they produce about themselves and their lives. The digital media platform gives the content scale - both the organic reach the influencers generate and the paid boosting of the content by the brand. In the case of Snapchat filters, the brand effectively ships an unfinished ad, inviting consumers to make their own appropriations and adaptations to the brand and to share them with peers within a platform where those creative appropriations can be monitored. This kind of participatory brand culture relies on our active and creative engagement.

Digital media make the promotional techniques of brands a ubiquitous part of platform interfaces and culture. As advertisers and users communicate within the same algorithmically governed engagement model, they each learn to adopt self-advantaging and promotional forms of presentation that cultivate desirable forms of attention and (in)visibility (Hearn, 2008; Banet-Weiser, 2012). Hearn (2008) develops the notion of the 'branded self' for describing the ways in which we draw on symbolic resources provided by brands for constructing ourselves, thereby eradicating any separation between 'authentic' and 'promotional' culture. On algorithmic digital platforms this involves more than just presenting our self as a brand. It is also the form of selfhood that emerges within a participatory and data-driven media environment where individuals learn to cultivate attention by making judgments about what kinds of performances are attracting attention within the algorithmic architecture of platform media. The branded self is both a cynical subject, as Hearn (2008) argues, and a logistical subject central to organising the digital media platform's participatory culture and data-processing power. The more we translate our lived experience into data, and the more we make deliberate judgments about how to 'format' ourselves in relation to the algorithmic character of media - to both attract and cultivate forms of attention we want and to avoid forms of attention we don't want - the more effectively media platforms can intervene in our public and private experiences. An algorithmic brand culture is therefore one in which the participatory creativity of users doubles as data that, over time, increases the capacity of platforms to manage and harness that participation to the commercial benefit of brands.

\section{Harnessing productive labour}


As previously mentioned, ideological critiques of brands in the twentieth century were accompanied by a political economy critique of 'audience labour' (Smythe, 1977). In this critique, the commodity that mass media organisations produce and sell is the living attention of audiences. Advertising works because audiences do the labour of watching advertisements and incorporating their messages into their identities and desires (Jhally, 1990; Jhally and Livant, 1986). Advertiser-funded media create value by packaging valuable audiences for sale to advertisers. In that sense, digital media industries produce a more valuable audience commodity by using data to target, simulate and customise. In the first instance, this commodity is more valuable because advertisers pay for less 'wasted eyeballs' - they are able to more precisely target their messages to specific audience members at particular times and places. In addition, digital media expands the form and amount of work that audiences do. Audiences no longer only do the work of watching advertisements and incorporating commercial appeals into their identities, they also do the work of being watched by producing content and data (Andrejevic, 2002). On advertiser-funded digital media platforms audiences both perform their identities and document everyday life as symbolic content that others consume. This both generates the platform-based sociality that sustains user engagement and translates their lived experiences into data. As they code everyday sociality into flows of images, video, likes, rankings, ratings and comments, they generate data about their preferences, actions, location, proximity to others, and mood, among an expanding array of data-points This data then is used to train predictive models and algorithms that hyper-target advertising and sustain engagement by optimising the content users see (Andrejevic, 2010). Thus, by participating on social media platforms, audiences create surplus value in the form of consumer intelligence, which is accrued by digital media platforms (Fuchs, 2015).

However, one aspect that arguably requires more attention in the context of critically conceptualising audience labour on algorithmic platforms is the role that audiences now play in the development of media infrastructure itself. While audiences did a lot of work watching television in the twentieth century, they didn't change the medium itself all that much (Brodmerkel and Carah 2016). But, in the case of digital media, the accumulation of data gradually trains platforms' algorithms and thereby changes the capacity of the medium to calculate. Furthermore, as audiences incorporate digital media devices into their public and private spaces and tether them to their bodies, they enhance the logistical capacity of media to monitor and intervene in everyday life. This mode of branding can be considered exploitative or alienating in the sense that our participation doubles as the labour of producing a media 
environment more capable of monitoring and optimising our attention, action and experience in the interests of marketers (Andrejevic 2011; Brodmerkel and Carah, 2016). Critical perspectives on branding therefore need to go beyond the account of audiences as labourers who do the work of consuming and producing media representations, to being crucial actors in the formation of the algorithmic and logistical capacities of digital media. As we upload images, rank, like, comment and so on, we are doing the work of training machines to classify, sort and organise our cultural experience, making moments of attention and action available to advertisers. In algorithmic brand cultures we do not just provide our attention. We also become part of the historical process of 'producing' and fine-tuning the marketing infrastructure we become embedded within.

\section{Media infrastructures are 'experience machines'}

Brands are moving beyond using only the participatory and algorithmic affordances of digital media to optimise the flow of symbolic messages. This can be observed in the shift from an 'exposure' to an 'engagement' audience marketplace (Napoli, 2011). Where once media could only be used to quantify and sell the reach of symbolic messages and their exposure to audiences, now a range of engagement metrics can be described and sold. This means that for brands media are not only channels through which symbols flow. Media are data-driven infrastructure and participatory interfaces for predicting and augmenting moment-to-moment experience of the social world. If the logic of 'traditional' brand culture has been to use media to control the representation of reality, it now shifts to using media as technologies for augmenting reality. As the industry catchphrase has it, 'everything is media' in the sense that anything - from living bodies to material objects - that can capture, channel, store, process or display information can potentially be incorporated into the structure of the brand. And so, branding becomes the process not just of attaching specific 'mythic' qualities to a product or experience, but the multidimensional process of using media to manage communication in general. This shift means that brands increasingly operate at the level of creating digitally augmented 'brand atmospheres'. And, consequently, that the work of building and managing brands involves making 'real world' actions and spaces a part of the brand infrastructure. Brands do this by capitalising on the connectivity and mobility of digital devices like smartphones, wearables, smart cameras and RFID tags - often in conjunction with purposebuilt activations. 
Brands use digital media as infrastructure for monitoring, anticipating and responding to 'real world' experiences - often in real time. This might be in the form of adapting the lighting or music of a spaces of consumption like a store or bar depending on the sensed profile or 'mood' of consumers. It might be by recommending nearby consumption experiences via an app as consumers scan an urban shopping precinct using a phone camera or map. Or it might be by offering consumers bespoke lenses or filters they can use to augment the images and videos they create as part of cultural events. Take Pepsi's so-called Bioreactive Concert as an instructive example (Dunne, 2014). It represents one of a myriad of brand activations that use digital technology to integrate the process of making brand value into the experience of cultural events and urban spaces. Digital technology allows brands to convert 'real world' events into an 'experience machine' (Frischman and Selinger, 2018) - an apparatus for anticipating and channelling the feeling, flow and action of social life. At the Pepsi concert attendees wore a wristband that converted physiological expressions into biometric datanoise, movement, sweat and heat. The data was fed into a media infrastructure created by the brand. Lights, music, rewards like free drinks and visualisations on big screens were all triggered by the collective biometrics of the audience. The brand here used digital technology to create an atmosphere, to make 'everything media' in the sense of making an open-ended experience available to the data-processing power of the brand's infrastructure. Rather than use media only to deliver symbolic messages, media here becomes an infrastructure that converts biometric reactions into stimuli that channel and harness the affective capacity of the audience. These kinds of infrastructures illustrate how brands use digital media to fine tune flows of feeling, affect and experience. It enables them to create digitally augmented 'brand atmospheres' by orchestrating the interplay between bodies, material environments, and digital media technologies and platforms.

Pepsi's Bioreactive Concert is emblematic of a trajectory where everyday objects like cars, fridges, watches, shoes, wristbands and so on get connected to media platforms, and become incorporated in the participatory and algorithmic logic of branding. These mobile and connected objects act as 'switches' or 'transfer points' between the living bodies and lived experience of consumers and the calculative capacity of digital media (Brodmerkel and Carah, 2016; Andrejevic and Burdon 2015; McStay, 2018). What this draws attention to is how, in the digital era, branding begins to resemble media engineering rather than just content creation. Critical accounts of branding need to acknowledge the central role that marketers now play in developing the logistical capacities of media to monitor, organise, 
shape, intervene in, and make predictions about the atmospheres within which we live our lives. The imperative that drives companies like Google, Facebook or Amazon is to make the world computationally comprehensible and to mediate, predict and - ultimately - control ever more aspects of consumers' lives (Zuboff, 2018). Funded by advertising budgets and often working in close collaboration with brands, these technology companies engineer platforms which have become historically significant sites for experiments with the material form and sensory capacities of media. They increasingly configure and interconnect digital devices, sensors, interfaces, algorithms and databases in order to shape and modulate social life. Digital media takes the form of a 'simulation machine' that entangles bodies, data and the environment with the objective to ensure the predictability of an ever-broader range of consumer behaviour (McKelvey et al., 2015; Sumartojo et al., 2016). All the major platforms are - in various ways - bio-reactive in that they sense our living bodies, process information about them, and learn to intervene in social life based on these inputs.

\section{Conclusion}

Brand critique in a digital, participatory media environment requires the further development of post-ideological perspectives. While 'traditional' symbolic-ideological approaches are still valuable, critical perspectives on brands and branding in 'algorithmic culture' need to contend with and investigate the interdependence between the new media environments' participatory and algorithmic affordances. The history and trajectory of branding should be approached by investigating marketers' attempts to make brands more reflexive and openended, encouraging consumer participation and converting these forms of engagement into increasingly granular data for segmenting and targeting audiences. What makes the current moment different is that the platform-driven digital media environment allows brands to integrate these two processes at scale. A critical theory of brands needs to examine how marketers use media as infrastructure for augmenting reality - for monitoring, shaping and experimenting with culture. Importantly, critical theories of algorithmic brand culture are crucial not just for gaining a more comprehensive understanding of brands' role as drivers of capitalist consumer culture. They also contribute to the larger goal of understanding the impact of digital media and the emerging platform economy on culture and politics more broadly. While much critical attention has been given to the algorithmic culture of digital media and its effects on our cultural and political processes, a blind-spot in the field is that 
many of the phenomena studied are a product of the advertiser-funded logic of these platforms.

Many of the critical issues discussed with regard to these platforms - the invasion of privacy, the potentially discriminating effects of hyper-targeting, the impact of algorithmic engagement models on attention and mood, the promotion of 'fake' or harmful content have their root cause in the promotional logic of engagement underlying the platforms' business models. Their algorithms have been developed and are continuously tuned with the interests of advertisers in mind. Consequently, a critical theory of platforms depends on a critical theory of algorithmic brand culture. The digital, participatory media environment provides marketers and advertisers with new and innovative opportunities for creating strategic and commercially-driven consumer experiences. Critical research into advertising and branding needs to engage with these new forms of creativity and control. Further investigations into the commercial interrelationships between brands and digital platforms and how they shape the interplay between consumer participation and algorithmic calculation are therefore urgently needed. 


\section{References}

Aaker, D. A. (1996). Building Strong Brands. New York; The Free Press.

Andrejevic, M. (2002). The work of being watched: Interactive media and the exploitation of self-exposure. Critical studies in media communication, 19(2), 230-248.

Andrejevic, M. (2009). Critical media studies 2.0: An interactive upgrade. Interactions:

Studies in Communication \& Culture, 1(1), 35-51.

Andrejevic, M. (2010). Surveillance and alienation in the online economy. Surveillance \& Society, 8(3), 278-287.

Andrejevic M. (2013). Infoglut: How Too Much Information Is Changing the Way We Think and Know. New York: Routledge.

Andrejevic, M. and Burdon, M. (2015). Defining the sensor society. Television and New Media, 16(1), 19-36.

Arvidsson, A. (2005). Brands a critical perspective. Journal of Consumer Culture, 5(2), 235258.

Arvidsson, A. (2006). Brands: Meaning and Value in Media Culture. Oxford: Routledge.

Banet-Weiser, S. (2012). Authentic: The Politics of Ambivalence in a Brand Culture. New York: New York University Press.

Barthes, R. (1977). The Rhetoric of the Image'. In Image - Music-Text. Hammersmith: Fontana Press, 32-51.

Beer, D. (2013). Popular Culture and New Media: The Politics of Circulation. London: Palgrave Macmillan.

Berthon, P., Holbrook, M. B., and Hulbert, J. M. (2003). Understanding and Managing the Brand Space. Sloan Management Review, 44(2), 49-54.

Brodmerkel, S. and Carah, N. (2016). Brand Machines, Sensory Media and Calculative Culture. London: Palgrave Macmillan.

Bucher, T. (2016). The algorithmic imaginary: Exploring the ordinary affects of Facebook algorithms. Information, Communication \& Society, 20(1), 30-44. 
Carah, N. and Dobson, A. (2016). Algorithmic hotness: Young women's "promotion" and "reconnaissance" work via social media body images. Social Media + Society, 2(4): 1-10.

Carah, N. (2017). Algorithmic brands: A decade of brand experiments with mobile and social media. New Media \& Society, 19(3): 384-400.

Carah, N. and Angus, D. (2018). Algorithmic brand culture: participatory labour, machine learning and branding on social media. Media, Culture \& Society, 40(2): 178-194.

Carducci, V. (2006). Culture Jamming: A Sociological Perspective. Journal of Consumer Culture, 6(1), 116-138.

Cederström, C. and Marinetto, M. (2013). Corporate social responsibility á la the liberal communist. Organization, 20(3), 416-432.

Cheney-Lippold, J. (2017). We Are Data: Algorithms and the Making of Our Digital Selves. New York: New York University Press.

Conejo, F. and Wooliscraft, B. (2015). Brands Defined as Semiotic Marketing System. Journal of Macromarketing, 35(3), 287-301.

Cotter, K. (2018). Playing the visibility game: How digital influencers and algorithms negotiate influence on Instagram. New Media \& Society, 21(4), 895-913.

Couldry, N. and Turow, J. (2014). Advertising, Big Data and the Clearance of the Public Realm: Marketers' New Approaches to the Content Subsidy. International Journal of Communication, 8, 1710-1726.

Dunne, C. (2014). Using Science To Throw A Killer Party. Fast Company. Retrieved from: https://www.fastcompany.com/3031268/using-science-and-skrillex-to-throw-a-killer-party. Last accessed: 30.07.2019.

Ewen, S. (1976). Captains of Consciousness: Advertising and the Social Roots of Consumer Culture. New York: McGraw-Hill.

Foster, R. (2008). Coca-globalisation: Following soft drinks from New York to New Guinea. New York: Palgrave-Macmillan.

Frank, T. (1997). The Conquest of Cool. Chicago: Chicago University Press. 
Frischmann, B. and Selinger, E. (2018). Re-Engineering Humanity. Cambridge: Cambridge University Press.

Fuchs, C. (2015). Dallas Smythe and digital labor, In Maxwell, R. (ed), Routledge companion to labor and media. New York: Routledge, pp. 51-62.

Gladwell, M. (1997). 'The Coolhunt'. The New Yorker. Retrieved from https://www.newyorker.com/magazine/1997/03/17/the-coolhunt. Last accessed 23.07.2019.

Goldman, R. and Papson, S. (1996). Sign Wars: The Cluttered Landscape of Advertising. New York: Guildford Press.

Hardy, J. (2015). Political economy approaches to advertising, in Wharton, C. (ed), Advertising: Critical Approaches. Abingdon: Oxon: Routledge, 65-84.

Hardy, J. (2017). 'Marketers' influence on media: Renewing the radical tradition for the digital age', in Hamilton, J. F., Bodie, R. and Korin, E. (eds), Critical Studies in Advertising: Critique and Reconstitution. New York: Routledge, 13-27.

Hawkins, G. (2009). The politics of bottled water: assembling bottled water as brand, waste and oil. Journal of Cultural Economy, 2(1-2), 183-195.

Hearn, A. (2008). Meat, Mask, Burden: Probing the contours of the branded 'self'. Journal of Consumer Culture, 8(2), 197-217.

Heath, J. and Potter, A. (2005). The Rebel Sell. How the counterculture became consumer culture. Chichester: Capstone Publishing.

Holt, D. B. (2002). 'Why Do Brands Cause Trouble? A Dialectical Theory of Consumer Culture and Branding. Journal of Consumer Research, 29(1), 70-90.

Jhally, S. (1990). The codes of advertising: fetishism and the political economy of meaning in the consumer society. Routledge: New York.

Jhally, S. and Livant, B. (1986). Watching as Working: The Valorization of Audience Consciousness. Journal of Communication, 36(3), 124-143.

Klein, N. (2000). No logo. London: Flamingo.

Kornberger, M. (2010). Brand Society: How Brands Transform Management and Lifestyle. Cambridge: Cambridge University Press. 
Lasn, K. (1999). Culture jam: The uncooling of America. New York: Eagle Brook.

Lazarsfeld, P. (1941). "Remarks on administrative and critical communications research."

Studies in Philosophy and Social Science, 9, 2-16.

Lewis, T. and Potter, E. (2013). Introducing Ethical Consumption. In Lewis, T. and Potter, E. (eds), Ethical Consumption: A Critical Introduction. New York: Routledge, 3-24.

Lury, C. (2009). Brand as assemblage: Assembling culture. Journal of Cultural Economy, 2 (1-2), 67-82.

Marcantonia, A., Abbott, D. And O'Driscoll, J. (2014). Remember those great Volkswagen ads? London: Merrell Publishers.

McKelvey, F., Tiessen, M., \& Simcoe, L. (2015). A Consensual Hallucination No More? The Internet as Simulation Machine. European Journal of Cultural Studies, 18(4-5), 577-594.

McStay, A. (2018). Emotional AI: The Rise of Empathetic Media. London: Sage.

Moor, L. (2003). "Branded Spaces: The Scope of New Marketing.” Journal of Consumer Culture, 3(1), 39-60.

Mosco, V. (2009). The Political Economy of Communication. London: Sage.

Murdock, G. and Golding, P. (2005). "Culture, Communications and Political Economy”, in Curran, J. and Gurevitch, M. (ed), Mass Media and Society, London: Hodder Arnold, 60-84.

Nadler, A. and McGuigan, L. (2018). An impulse to exploit: the behavioral turn in datadriven marketing. Critical Studies in Media Communication, 35(2), 151-165.

Napoli, P. M. (2011). Audience Evolution: New Technologies and the transformation of media audiences. New York: Columbia University Press.

Packard, V. (1957). The Hidden Persuaders. London: Pelican.

Prahalad, C. K. and Ramaswamy, V. (2004). The Future of Competition: Co-creating Unique Value with Customers. Boston: Harvard Business School.

Ritzer, G. (1992). The McDonaldization of Society. Thousand Oaks: Pine Forge Press.

Serazio, M. (2013). Your ad here: The cool sell of guerrilla marketing. New York: New York University Press. 
Smythe, Dallas W. (1977). Communications: Blindspot of Western Marxism. Canadian Journal of Political and Social Theory, 1(3), 1-27.

Striphas, T. (2015). Algorithmic culture. European Journal of Cultural Studies, 18(4-5), $395-$ 412.

Sumartojo, S., Pink, S., Lupton, D. and Heyes LaBond, C. (2016). 'The affective intensities of datafied space'. Emotion, Space and Society, 21, 33-40.

Terranova, T. (2000). Free Labor: Producing Culture for the Digital Economy. Social Text $63,18(2), 33-58$.

Turow, J. (2011). The Daily You: How the new advertising industry is defining your identity and worth. New Haven: Yale University Press.

van der Nagel, E. (2018). 'Networks that work too well': intervening in algorithmic connections. Media International Australia, 168(1), 81-92.

Vargo S. and Lusch R. (2004). Evolving to a New Dominant Logic for Marketing. Journal of Marketing, 68(1), 1-17.

Wernick, A. (1991). Promotional Culture. Advertising, Ideology and Symbolic Expression. London: Sage.

Zuboff, S. (2018). The Age of Surveillance Capitalism: The Fight for a Human Future at the New Frontier of Power. New York: Public Affairs.

Zwick, D., Bonsu S. and Darmody A. (2008). Putting Consumers to Work: 'Co-creation' and new marketing govern-mentality. Journal of Consumer Culture, 8(2), 163-197.

Zwick, D. and Knott, D. (2009). Manufacturing Customers: The database as a new means of production. Journal of Consumer Culture, 9(2), 221-247. 